\title{
CORONARY ARTERY BYPASS GRAFTING ON THE BEATING HEART WITHOUT THE USE OF EXTRACORPOREAL CIRCULATION: REVIEW OF 2052 CASES
}

Oguz Tasdemir, MD

Kerem M. Vural, MD

Haldun Karagoz, MD

Kemal Bayazit, MD

\begin{abstract}
Objective: A total of 2052 patients operated on with the off-pump technique (coronary artery bypass grafting on the beating heart without the use of extracorporeal circulation) between June 1993 and March 1996 are retrospectively reviewed. Predictors for early mortality, perioperative myocardial infarction, and low cardiac output state were statistically analyzed. Method: Our indications for an off-pump procedure were either patients with technically suitable coronary lesions (the vast majority) or patients who could not tolerate cannulation, hypothermia, or cardiopulmonary bypass because of the poor left ventricular function (198 patients) and/or associated diseases or conditions (73 patients). Results: Overall operative mortality was $1.9 \%$ and perioperative myocardial infarction occurred in 59 patients $(2.9 \%)$. According to logistic regression analysis, associated bronchial asthma $(p=0.0001)$, hypertension $(p=0.05)$, poor quality of the left anterior descending artery $(p=\mathbf{0 . 0 2})$, and ungrafted circumflex coronary artery disease $(p=0.007)$ were the early mortality predictors. Nonbypassed circumflex disease was also associated with a high incidence of perioperative myocardial infarction and low cardiac output state. No homologous blood or packed red cell transfusion was required in $74.2 \%$ of the patients. Conclusion: On the basis of the presented data, off-pump coronary artery bypass grafting appeared to be a safe and effective technique in selected patients with appropriate coronary lesions. (J Thorac Cardiovasc Surg 1998;116:68-73)
\end{abstract}

$\mathrm{R}$ ecently, coronary artery bypass grafting (CABG) on the beating heart without the use of the pump-oxygenator (off-pump CABG technique) was offered as an alternative to the standard on-pump technique in selected and suitable cases. Although some technical limitations exist with the off-pump technique, some theoretical advantages over the standard cardiopulmonary bypass (CPB) procedure can be identified as well. The off-pump technique seems more logical in patients with a poor ventricle or in some instances in which $\mathrm{CPB}$, hypothermia, or cannulation is not desirable. An important reduction in the homologous transfusion requirements

From the Cardiovascular Surgery Department at Türkiye Yüksek Ihtisas Hospital, Ankara, Turkey.

Received for publication July 1, 1997; revisions requested Oct. 14, 1997; revisions received Feb. 17, 1998; accepted for publication Feb. 23, 1998.

Address for reprints: Kerem M. Vural, MD, N. Tandogan cad. 5/6 Kavaklidere 06540, Ankara, Turkey.

Copyright (C) 1998 by Mosby, Inc.

$0022-5223 / 98 \$ 5.00+0 \quad \mathbf{1 2 / 1 / 8 9 8 0 4}$ and a smoother early postoperative period are also expected. ${ }^{1}$ Further, the economic aspect of "offpump" surgery is striking. ${ }^{2}$ However, the safety and efficacy of the procedure are still to be determined.

\section{Patients and methods}

Patient population. Between June 1993 and March 1996, 2052 patients underwent isolated CABG on the beating heart without the use of extracorporeal circulation (off-pump technique). Off-pump surgery comprises about one third of our total CABG practice. Of the 2052 patients, 1580 were male $(77 \%)$ and 472 were female $(23 \%)$. Mean age (with standard deviation) was $54 \pm 9$ years and the range was between 28 and 80 years. Only $21 \%$ of patients had a normal preoperative left ventriculogram, having a left ventricular end-diastolic pressure (LVEDP) below $20 \mathrm{~mm} \mathrm{Hg}$ and a left ventricular segmental wall motion score of 7 (for information about the scoring system, see the appendix). The great majority (1424 patients, 69\%) had segmental wall motion abnormalities (LVEDP, 21 to $29 \mathrm{~mm} \mathrm{Hg}$; segmental wall motion score, 8 to 11) and another $198(9.6 \%)$ patients had severely impaired left ventricular function (LVEDP exceeding $30 \mathrm{~mm} \mathrm{Hg}$ and/or segmental wall motion score 12 or greater, with a left ventricular ejection fraction less than $30 \%$ ). An intraaortic balloon was inserted before the 
Table I. Preoperative associated conditions in 73 patients

\begin{tabular}{lc}
\hline & No. \\
\hline Severe chronic obstructive pulmonary disease & 18 \\
Severe carotid disease & 11 \\
Chronic renal failure (on dialysis) & 8 \\
Bronchial asthma & 5 \\
Neurologic sequelae & 5 \\
Calcified ascending aorta & 4 \\
Hypothyroidism & 4 \\
Hyperthyroidism & 3 \\
Abdominal aortic aneurysm & 3 \\
Parkinson's disease & 2 \\
Nephrectomy & 1 \\
Waldenström's macroglobulinemia & 1 \\
Familial Mediterranean fever & 1 \\
Endometrial cancer & 1 \\
Laryngeal cancer & 1 \\
Hodgkin's lymphoma & 1 \\
Urinary bladder cancer & 1 \\
Aneurysmal dilatation of ascending aorta & 1 \\
Descending aortic aneurysm & 1 \\
Type B dissection & 1 \\
\hline
\end{tabular}

operation in 14 hemodynamically unstable patients $(0.7 \%)$. Seventy-three patients had associated diseases/ conditions in which cannulation, hypothermia, or CPB was thought to be disadvantageous (Table I).

Indications for off-pump CABG. Off-pump surgery was thought to be indicated in three types of patients.

1. Candidates for routine $C A B G$, technically suitable for off-pump surgery. Candidates for routine $\mathrm{CABG}$ are the patients with significant lesions of the proximal left anterior descending coronary artery (LAD) not suitable for percutaneous transluminal coronary angioplasty (PTCA), with or without right coronary artery involvement. Circumflex coronary artery branches coursing adjacent to the diagonal vessels on the anterolateral aspect of the left ventricle, and sometimes the right posterior descending artery, could also be exposed and grafted by means of the off-pump technique through a median sternotomy (Table II).

2. Patients with poor ventricles who may not tolerate $C P B$ or aortic crossclamping. In the poor ventricle group, if the vessel appeared nongraftable on angiography, we preferred not to revascularize a poor-quality, thin, minor circumflex branch. Instead, we directly bypassed the LAD system (and right coronary artery, if needed) using the off-pump technique.

3. Patients with associated diseases or conditions in whom $C P B$, hypothermia, or cannulation was not desirable. Such was the case in $73(3.6 \%)$ patients as presented in Table I.

Complete revascularization was the goal in all but the last two groups $(n=227,17.8 \%)$. In the latter, if a patient had inaccessible or ungraftable circumflex disease, grafting only of the LAD coronary artery (and right coronary artery, if needed) was thought to be appropriate and was performed in the expectation of improvement in the patients' symptoms and life expectancy (see Discussion).
Table II. Operative data

\begin{tabular}{lrc}
\hline & No. & $\%$ \\
\hline Single graft & 1261 & 61.5 \\
Two grafts & 715 & 34.8 \\
LAD+RCA system & 619 & \\
LAD+ diagonal & 85 & \\
LAD+Cx system & 11 & \\
Three grafts & 72 & 3.5 \\
LAD+RCA+ diagonal & 57 & \\
LAD+RCA+Cx system & 7 & \\
LAD+RCA+RCA branches & 5 & \\
LAD+LAD (sequential)+RCA system & 3 & \\
Four grafts & 4 & 0.2 \\
LAD+diagonal+Cx branch+RCA & 2 & \\
LAD+Cx branch+RCA+RCA branch & 2 & \\
Reoperations & 22 & \\
Endarterectomies & 34 & \\
Closed & & \\
RCA & 25 & \\
LAD & 3 & \\
Open & & \\
LAD & 6 & \\
\hline
\end{tabular}

$L A D$, Left anterior descending coronary artery; $R C A$, right coronary artery; $C x$, circumflex.

Operative technique. Our operative technique was described in detail in our previous publications. ${ }^{1,3}$ In brief, after median sternotomy, wet gauze pads or retracting sutures were placed for purposes of fixation or exposure. If copious rinsing with warm saline solution was insufficient to control bleeding, we applied an atraumatic bulldog clamp about $1.5 \mathrm{~cm}$ proximal to the coronary artery (together with the surrounding fat pad) during the anastomosis. A simple intermittent regional immobilization method was applied to facilitate the anastomosis. During the manipulation of the native coronary vessel (i.e., arteriotomy, needle passage), the surgeon and the first assistant grasped the opposite sides of adjacent epicardium with pick-ups, pulling up with slight tension. Thus about 2 to $3 \mathrm{~cm}$ of epicardial segment was rendered motionless, with the heart beating underneath. After the anastomosis was completed but before the suture was tied, a 1 or 1.5 $\mathrm{mm}$ probe was passed through the coronary artery, not only to check the anastomosis, but also to dilate possible native coronary vessel spasm caused by the temporary hemostatic bulldog clamp application

Our criteria for a perioperative myocardial infarction were as follows: (1) a newly formed $\mathrm{Q}$ wave on the electrocardiogram; (2) creatine kinase MB levels exceeding $50 \mathrm{U} / \mathrm{L}$, especially with a concordant later increase in aspartate aminotransferase; (3) poor R-wave progression in precordial leads (so-called $\mathrm{R}$ amputation). Early mortality, perioperative myocardial infarction, and low cardiac output state were recorded for the first postoperative month. Operative data are shown in Table II.

Statistical analysis. Means are presented \pm 1 standard deviation and proportions are accompanied by $95 \%$ confidence intervals $(\mathrm{CI})$. Predictors for mortality, perioperative myocardial infarction, and nonfatal low cardiac output state 
Table III. Causes of early death in 2052 patients

Perioperative myocardial infarction 13

Low cardiac output

Sepsis

Permanent neurologic damage, coma

Respiratory insufficiency

Persistent malignant arrhythmias

Bleeding

Sudden death (undetermined)

Total

6

6

4

4

2

2

$\frac{2}{39}$

were first analyzed by Fisher's exact test (univariable analysis). Odds ratios with $95 \%$ confidence limits were also represented. Logistic regression analysis (multivariable analysis) was then performed for ranking the mortality predictors determined by univariable analysis. Statistical analysis was performed and interpreted by a certified statistician (see acknowledgments). All statistics were obtained by SPSS software (version 6.0, SPSS Inc., Chicago, Ill.).

\section{Results}

Mortality analysis. Overall hospital mortality was $1.9 \%$ (39 patients; CI, $1.4 \%$ to $2.6 \%$ ). Mortality rates for different indication groups are as follows: $1.67 \%$ (CI, $1.2 \%$ to $2.2 \%$ ) for group I (candidates for routine $\mathrm{CABG}$, technically suitable), $3 \%(\mathrm{CI}$, $0.5 \%$ to $6.0 \%$ ) for group II (patients with very poor preoperative left ventricular function), and $2.7 \%$ (CI, $0.4 \%$ to $5.6 \%$ ) for group III (patients with associated conditions contraindicating $\mathrm{CPB}$, as described in Table I). Causes of death are shown in Table III. Perioperative myocardial infarction was the primary cause of death (33\% of early deaths).

According to univariable analysis, age over 70 years, associated bronchial asthma or hypertension, poor quality of the LAD coronary artery or caliber below $1.5 \mathrm{~mm}$, and nongrafted circumflex artery disease were associated with higher mortality (Table IV, left columns). After filtering a great number of variables to be tested by univariable analysis, we entered the remaining variables into multivariable analysis for definitive evaluation. Multivariable (logistic regression) analysis showed that associated bronchial asthma was the most important early mortality predictor, followed by nongrafted disease of the circumflex coronary artery. Some of the variables (age over 70 years, small LAD caliber) were excluded from the mortality predictors, depending on the results derived from the multivariable analysis (Table V).

Early postoperative complications. Early complications are summarized in Table VI. The most prevalent complication was nonfatal perioperative myocardial infarction. Periprocedural nonfatal low cardiac output state was another complication that was frequently encountered.

Perioperative myocardial infarction and the incremental risk factors. Fifty-nine patients $(2.9 \%$; CI, $1.8 \%$ to $3.6 \%$ ) had perioperative myocardial infarction, as seen in Table VI. Emergency operations (mostly after unsuccessful PTCA) and nongrafted circumflex disease were associated with perioperative myocardial infarction according to the univariable analysis (Table IV, middle columns).

Low cardiac output state and the incremental risk factors. Apart from the preoperative prophylactic use of the intraaortic balloon pump in 14 patients $(0.7 \%$; CI, $0.4 \%$ to $1.2 \%)$ with severely impaired left ventricular function, 28 additional patients $(1.4 \%$; CI, $0.9 \%$ to $2.0 \%$ ) needed balloon pump support in the early postoperative period. Nonfatal postoperative low cardiac output state developed in 58 patients (2.8\%; CI, $1.2 \%$ to $3.6 \%$, Table VI). Predictors for nonfatal postoperative low cardiac output state were age over 70 years, preoperative poor left ventricular function (as described above), a poor quality and/or small caliber LAD artery, and nongrafted disease of the circumflex system (Table IV, right columns).

Homologous transfusion requirements. The average first day and total chest tube drainage was $829 \pm 345 \mathrm{ml}$ and $932 \pm 395 \mathrm{ml}$, respectively. An average of $0.4 \pm 0.86$ units of homologous packed red cells per patient and $1.9 \pm 1.16$ units of fresh frozen plasma per patient were administered. No homologous blood or packed red cell transfusion was required in $74 \%$ of the patients.

\section{Discussion}

In previous reports, the efficacy of $\mathrm{CABG}$ without the use of CPB has been evaluated. Archer, Ott, and Parravicini ${ }^{4}$ reported significantly lower homologous transfusion needs in 191 patients with a high perioperative infarction rate of $18.7 \%$. Laborde, Abdelmequid, and Piwnica ${ }^{5}$ reported no deaths or perioperative myocardial infarctions in 38 patients. Benetti, Naselli, and $\mathrm{Wood}^{6}$ operated on 700 patients in 12 years with $1 \%$ mortality. In that report, economic aspects of the procedure and very low transfusion requirements were emphasized. In the follow-up angiograms, $93 \%$ of the left internal thoracic artery grafts and $87.5 \%$ of the saphenous vein grafts were patent. Moshkovitz, Lusky, and $\mathrm{Mohr}^{7}$ presented their experience in 220 patients with a univariable analysis of the early unfavorable outcomes, reporting a mortality rate of $3.2 \%$ and a nonfatal perioperative myocardial infarction incidence of $2.7 \%$. More recently, in the study 
Table IV. Univariate analysis for the risk factors

\begin{tabular}{|c|c|c|c|c|c|c|c|c|c|}
\hline \multirow[b]{2}{*}{ Risk factor } & \multicolumn{3}{|c|}{ Early mortality } & \multicolumn{3}{|c|}{ Perioperative myocardial infarction } & \multicolumn{3}{|c|}{ Low cardiac output } \\
\hline & $p$ Value & $\begin{array}{l}\text { Odds } \\
\text { ratio }\end{array}$ & $95 \% C I$ & $p$ Value & $\begin{array}{l}\text { Odds } \\
\text { ratio }\end{array}$ & $95 \% C I$ & $p$ Value & $\begin{array}{l}\text { Odds } \\
\text { ratio }\end{array}$ & $95 \% C I$ \\
\hline \multicolumn{10}{|l|}{ Preoperative } \\
\hline Bronchial asthma (0.4) & $0.0003^{*}$ & 49.9 & 8.01-307.4 & 0.08 & 16.4 & $1.8-153.8$ & 0.3 & 3 & $0.3-27.2$ \\
\hline Hypertension (29) & $0.04^{*}$ & 1.9 & $0.9-3.5$ & 0.2 & 0.61 & $0.2-1.8$ & 0.2 & 1.2 & $0.8-1.9$ \\
\hline Elderly-age over 70 yr (3.6) & $0.05^{*}$ & 1.9 & $0.9-3.5$ & 0.5 & 1.4 & $0.2-10.8$ & $0.04^{*}$ & 2.2 & $0.9-5.1$ \\
\hline Poor left ventricle—see text (9.6) & 0.6 & 1.3 & $0.5-3.4$ & 0.6 & 1 & $0.2-4.4$ & $0.03^{*}$ & 1.7 & $0.9-3.1$ \\
\hline Obesity (4.8) & 0.4 & 1.6 & $0.5-5.5$ & 0.6 & 1.4 & $0.2-9.8$ & 0.5 & 2.1 & $1.1-4.2$ \\
\hline Hyperlipidemia (13.8) & 0.6 & 1.2 & $0.5-3.4$ & 0.7 & 1.2 & $0.2-10.1$ & 0.6 & 1.2 & $0.5-3.4$ \\
\hline Left main coronary disease $(0.5)$ & 0.8 & 1.3 & $0.4-1.8$ & 0.9 & 0.3 & $0.03-1.9$ & 0.07 & 2.4 & $0.9-6.4$ \\
\hline Mild LAD stenosis, $<75 \%$ & 0.5 & 1.1 & $0.5-2.3$ & 0.5 & 0.9 & $0.3-2.8$ & 0.5 & 1 & $0.6-1.7$ \\
\hline Total LAD occlusion (23.6) & 0.7 & 0.8 & $0.4-1.8$ & 0.8 & 1.1 & $0.4-3.0$ & 0.2 & 1.4 & $0.9-2.2$ \\
\hline Mild RCA stenosis (8.6) & 0.8 & 1.1 & $0.4-3.1$ & 0.4 & 1.6 & $0.4-6.2$ & 0.5 & 0.7 & $0.4-1.5$ \\
\hline Total RCA occlusion (19.1) & 0.6 & 1.9 & $0.9-4.5$ & 0.8 & 0.8 & $0.2-2.7$ & 0.2 & 1.4 & $0.9-2.4$ \\
\hline Severe COPD (12) & 0.1 & 1.2 & $0.5-3.4$ & 0.4 & 0.9 & $0.3-2.1$ & 0.8 & 1.1 & $0.4-3.0$ \\
\hline Carotid artery disease (5.9) & 0.08 & 2.4 & $0.9-6.4$ & 0.4 & 1.1 & $0.8-3.1$ & 0.2 & 0.61 & $0.2-1.8$ \\
\hline \multirow{2}{*}{\multicolumn{10}{|c|}{ Operative }} \\
\hline & & & & & & & & & \\
\hline Ignored Cx system disease (17.8) & $0.0009^{*}$ & 2.9 & $1.5-5.6$ & $0.005^{*}$ & 1.2 & $0.4-3.58$ & $0.001^{*}$ & 2.4 & $1.6-3.8$ \\
\hline Poor LAD quality (6.8) & $0.02^{*}$ & 3 & $1.3-7.0$ & 0.6 & 0.72 & $0.1-5.6$ & $0.05^{*}$ & 1.5 & $0.7-3$ \\
\hline $\mathrm{LAD}<1.5 \mathrm{~mm}(11.8)$ & $0.04 *$ & 2.2 & $1.0-4.7$ & 0.4 & 0.9 & $0.2-3.7$ & $0.05^{*}$ & 1.3 & $0.7-2.3$ \\
\hline Emergency operation $(0.5)$ & 0.8 & 3.2 & $0.9-6.1$ & $0.05^{*}$ & 13.1 & $1.5-117.8$ & $0.0004^{*}$ & 24.9 & $4.5-137.9$ \\
\hline Reoperation (1.1) & 0.7 & 3.2 & $0.8-14.1$ & 0.6 & 1.1 & $0.8-3.1$ & 0.1 & 1.1 & $0.5-2.3$ \\
\hline Coronary endarterectomy (1.7) & 0.4 & 2.1 & $1.1-4.2$ & 0.7 & 1.2 & $0.4-3.0$ & 0.4 & 1.5 & $0.3-6.7$ \\
\hline Number of grafts & 0.3 & 1.6 & $0.8-2.8$ & 0.1 & 1.1 & $0.5-2.3$ & 0.2 & 1.3 & $0.4-2.7$ \\
\hline Type of grafts & 0.9 & 1.3 & $0.5-3.3$ & 0.3 & 1.4 & $0.9-4.5$ & 0.1 & 1.1 & $0.4-2.2$ \\
\hline Bilateral ITA (0.4) & 0.4 & 1.4 & $0.4-3.2$ & 0.2 & 1.2 & $0.3-2.8$ & 0.4 & 2.1 & $1.1-4.2$ \\
\hline
\end{tabular}

Numbers in parentheses in the first column indicate the parameter's frequency in percentage. $C I$, Confidence intervals; $L A D$, left anterior descending coronary artery; $R C A$, right coronary artery; $C O P D$, chronic obstructive pulmonary disease; $C x$, circumflex coronary artery; ITA, internal thoracic artery. $* p<0.05$.

of Buffolo and coworkers, ${ }^{2}$ with a mortality rate of $2.5 \%$ and a perioperative myocardial infarction rate of $4.8 \%$, CABG without $\mathrm{CPB}$ was presented as a safe and cost-effective procedure with proper selection of the patients. A significant decrease in homologous blood transfusion was emphasized in many previous publications, including ours. ${ }^{1,4,6}$ Advantages are decreasing the huge demands on the blood bank and reducing the risk of transmitting diseases such as acquired immunodeficiency syndrome, hepatitis $\mathrm{B}$ and $\mathrm{C}$, or the recently described graft-versus-host phenomenon seen with massive transfusion of homologous blood.

The current mortality rate among our patients is $1.9 \%$ and the perioperative myocardial infarction rate is $2.9 \%$. Univariable analysis showed no association between poor ventricular function and early hospital mortality. In a study by Magovern and colleagues, ${ }^{8}$ CABG (with standard CPB technique) was been offered as an alternative surgical approach to patients with congestive heart failure with a good early and midterm outcome expectancy. In this high-risk group, operative mortality was $4 \%$. Offpump CABG may offer even lower mortality rates
Table V. Logistic regression analysis for early mortality predictors

\begin{tabular}{llllll}
\hline \multicolumn{1}{c}{ Variable } & $B$ & SE & val & \multicolumn{1}{c}{$R$} & Exp $(B)$ \\
\hline Assoc. bronchial asthma & 3.8 & 0.98 & 0 & 0.193 & 46.012 \\
Nongrafted Cx system disease & 0.95 & 0.35 & 0 & 0.1225 & 2.5825 \\
Associated hypertension & 0.67 & 0.34 & 0.1 & 0.0744 & 1.96 \\
Poor LAD vessel quality & 1.1 & 0.48 & 0 & 0.0938 & 2.9796 \\
\hline
\end{tabular}

$S E$, Standard error; $C x$, circumflex; $L A D$, left anterior descending.

and encourage the surgeon to consider CABG before other therapeutic modalities such as transplantation, cardiomyoplasty, or medical management. Another interesting finding was that the logistic regression analysis identified nongrafted circumflex stenoses as a risk factor. That brings up another issue that may relate to the long-term follow-up. In patients with poor ventricular function or associated problems that make standard techniques hazardous, bypassing only the LAD artery seems to be an acceptable approach, but only if circumflex disease is nongraftable. In those, we preferred not to revascularize poor-quality, thin, minor circumflex branches. 
Table VI. Early postoperative complications

\begin{tabular}{|c|c|c|c|}
\hline & No. & $\%$ of total & $C I$ \\
\hline Perioperative myocardial infarction & 59 & 2.9 & $1.8-3.6$ \\
\hline Nonfatal low cardiac output state & 58 & 2.8 & $2.2-3.7$ \\
\hline Requiring inotropic support & 30 & 1.5 & \\
\hline $\begin{array}{l}\text { Requiring inotropic plus } \\
\text { mechanical support }\end{array}$ & 28 & 1.4 & \\
\hline Revisions & 20 & 0.9 & $0.6-1.5$ \\
\hline For surgical bleeding & 12 & 0.6 & \\
\hline For relief of cardiac tamponade & 4 & 0.2 & \\
\hline For regrafting & 4 & 0.2 & \\
\hline Infection & 10 & 0.5 & $0.2-0.9$ \\
\hline Mediastinitis & 4 & 0.2 & \\
\hline Sepsis & 6 & 0.3 & \\
\hline Rhythym disturbances & 46 & 2.2 & $1.7-3.0$ \\
\hline Atrial fibrillation & 34 & 1.7 & \\
\hline Ventricular fibrillation & 5 & 0.2 & \\
\hline $\begin{array}{l}\text { Atrioventricular complete } \\
\text { heart block }\end{array}$ & 5 & 0.2 & \\
\hline Sick sinus syndrome & 2 & 0.1 & \\
\hline Neurologic complications & 16 & 0.8 & $0.5-1.3$ \\
\hline Transient & 6 & 0.3 & \\
\hline Permanent & 10 & 0.5 & \\
\hline Generalized (coma) & 4 & 0.2 & \\
\hline Focal (hemiplegia) & 6 & 0.3 & \\
\hline $\begin{array}{l}\text { Acute renal failure necessitating } \\
\text { dialysis }\end{array}$ & 5 & 0.2 & $0.1-0.6$ \\
\hline $\begin{array}{l}\text { Respiratory failure prolonged } \\
\text { intubation/tracheostomy }\end{array}$ & 8 & 0.4 & $0.2-0.8$ \\
\hline Pneumothorax & 6 & 0.3 & $0.1-0.7$ \\
\hline
\end{tabular}

CI, $95 \%$ confidence interval.

Instead, we directly bypass the LAD system (and right coronary artery, if needed) using the off-pump technique, rather than taking the risk of $\mathrm{CPB}$ and aortic crossclamping, or pronouncing these patients unsuitable for surgical treatment. In such situations, off-pump surgery is performed with the aim to improve the patients' symptoms and life expectancy. Yet, a suboptimal result must be anticipated. Certainly, complete revascularization is essential in those that have graftable circumflex disease. It is preferable to completely revascularize as much as possible those patients with poor left ventricular function in the anticipation that there are islands of viable myocardium scattered in and around the areas of scar, trying to retrieve as much viable myocardium as possible (Lytle BW. Personal communication, 1996).

Associated disorders may possess risk-increasing effects for standard CPB. Bronchial asthma was found to be an important early predictor of mortality. On the other hand, patients with a history of chronic obstructive pulmonary disease and showing spirometric data below $50 \%$ of predicted could be referred for offpump surgery, because the adverse effects of CPB in patients with limited pulmonary reserve were avoided. Similarly, in patients with chronic renal failure supported by dialysis or patients with carotid artery disease, off-pump coronary revascularization could be expected to be relatively less risky. Interestingly, hypertension was a predictor of early mortality. One can speculate that the increased left ventricular mass with limited coronary supply would poorly tolerate even the short periods of coronary blood flow interruption during the anastomosis. Until objective results are obtained to support this hypothesis, it must be kept in mind that hypertensive patients may have lesser tolerance for off-pump procedures. The incidence of atrial fibrillation was relatively low in patients treated offpump, most probably because of liberal use of digitalis and $\beta$-blocking agents in the perioperative period.

Another question may arise about our patient population. Off-pump surgery comprises about one third of our total CABG practice. In fact, our single-vessel CABG population is greater than those in the United States and other western countries. Most patients with single vessel (LAD) disease are referred for surgical revascularization by our cardiology department, because our institutional policy is not to supply surgical back-up for PTCA of proximal LAD lesions. The reasons for this are as follows: Although obstructive disease of the LAD system clearly has a poorer prognosis than that of the right or circumflex systems, the LAD system is the easiest with which to obtain the best operative results. In our opinion, current results support the approach that surgical revascularization with an internal thoracic artery graft for single-vessel disease involving the LAD yields a better long-term, event-free survival than continued medical treatment or PTCA and is the treatment of choice. ${ }^{9-11}$ The periprocedural myocardial infarction rate in PTCA may reach 5.6\% ${ }^{12}$ Furthermore, restenosis remains the Achilles heel of PTCA, and a restenosis rate of $45.4 \%$ has been reported in LAD lesions. ${ }^{13}$ In single vessel disease, 5 -year survival was found to be $100 \%$ for CABG and $96.5 \%$ for PTCA. ${ }^{9}$ In the same study, 5 -year event-free survival was $100 \%$ for CABG and only $52.2 \%$ for PTCA $(p<0.01)$.

Minimally invasive coronary artery bypass grafting (MIDCAB) procedures are of increasing interest today. A standard median sternotomy, rather than a minithoracotomy, may be preferable for precise harvesting of the internal thoracic artery. With the minithoracotomy techniques, harvesting the internal thoracic artery may be difficult and cumbersome. Damage to this invaluable graft resulting from excess manipulation may decrease the efficiency of the pro- 
cedure. Furthermore, with a limited thoracotomy technique, the distal muscular part of the internal thoracic artery, which is of poor quality to be a bypass conduit, is used. Undivided proximal branches may cause steal phenomena as well. Often, the anastomosis is done at a very distal part of $\mathrm{LAD}$, leaving a large area of myocardium perfused retrogradely. Ischemic preconditioning is another popular issue. Occluding the coronary vessel to be grafted for 3 to 5 minutes before anastomosis has recently been advocated by some surgeons. However, the distal anastomosis itself generally takes about 5 to 7 minutes to construct, so we think such an attempt is unnecessary. Intraluminal shunts, adjunctive adenosine, other sophisticated immobilizing or hemostatic devices (Octopus [Utrecth, The Netherlands], USCI [Bard USCI Div., Billerica, Mass.], CTS [CTS Microelectronics, Inc., West Lafayette, Ind.]) are subjects of great enthusiasm and interest today. However, we are confident of the technique described herein. It is cheap and easily applicable.

In technically suitable cases, which consist of those with a graftable LAD artery and without circumflex system disease, off-pump CABG could be considered a safe and efficient technique. It is not only practical and economical, but also useful if cannulation, hypothermia, or CPB is associated with a major risk. Economic advantages should also be kept in mind in developing countries. However, the procedure is technically demanding, limiting its use as a universally reproducible procedure. Patient selection and surgical experience are of pivotal importance and long-term results are yet to be determined. Randomized trials with the early assessment of graft patency by control angiograms or noninvasive methods (such as thermal imaging or transthoracic duplex scanning) are absolutely necessary. An analysis of long-term results with symptomatologic, angiographic, and clinical outcomes with actuarial, symptom-free, and event-free survival analyses is the subject of an ongoing study in our institution. We believe that, despite its limitations, this technique will become more and more important in the future with its potential advantages. Besides, many invaluable lessons can be learned from the experience with the off-pump technique, and this experience may be the first step of future MIDCAB procedures.

The consultant statistician, Attila Elhan (Department Biostatistics, Ankara University, School of Medicine), conducted the scientific analysis of the study data.

\section{REFERENCES}

1. Vural KM, Tasdemir O, Karagöz H, et al. Comparison of the early results of coronary artery bypass grafting with and without extracorporeal circulation. Thorac Cardiovasc Surg 1995;43:320-5.

2. Buffolo E, Andrade JCS, Branco JNR, et al. Coronary artery bypass grafting without cardiopulmonary bypass. Ann Thorac Surg 1996;61:63-6.

3. Vural KM, Tasdemir O, Karagöz HY, Bayazit K. Avoiding early or late failure in off-pump coronary artery bypass grafting [letter]. Ann Thorac Surg 1996;43:320-5.

4. Archer R, Ott DA, Parravicini R. Coronary artery revascularization without cardiopulmonary bypass. Tex Heart Inst J 1984;11:52-7.

5. Laborde F, Abdelmequid I, Piwnica A. Aortocoronary bypass without extracorporeal circulation: Why and when? Eur J Cardiothorac Surg 1989;3:152-5.

6. Benetti FJ, Naselli G, Wood M. Direct myocardial revascularization without extracorporeal circulation: experience in 700 patients. Chest 1991;100:312-6.

7. Moshkovitz Y, Lusky A, Mohr R. Coronary artery bypass without cardiopulmonary bypass: analysis of short-term and mid-term outcome in 220 patients. J Thorac Cardiovasc Surg 1995;110:979-87.

8. Magovern JA, Magovern GJ, Maher TD Jr, et al. Operation for congestive heart failure: transplantation, coronary artery bypass, and cardiomyoplasty. Ann Thorac Surg 1993;56:418-25.

9. Akins CW. Controversies in myocardial revascularization: coronary artery surgery for single-vessel disease. Semin Thorac Cardiovasc Surg 1994;6:109-15.

10. Loop FD, Lytle BW, Cosgrove DM, et al. Influence of the internal mammary artery graft on 10-year survival and other cardiac events. N Engl J Med 1986;316:1-6.

11. Lytle BW, Loop FD, Cosgrove DM, et al. Long-term (5 to 12 years) serial studies of internal mammary and saphenous vein coronary bypass grafts. J Thorac Cardiovasc Surg 1985;89:24-858.

12. Acinapura AJ, Cunningham JN Jr, Jacobowitz IJ, et al. Efficacy of percutaneous transluminal coronary angioplasty compared with single vessel bypass. J Thorac Cardiovasc Surg 1985;89:35-41.

13. Hirshfeld J Jr, Schwartz JS, Jugo R, et al. Restenosis after coronary angioplasty: a multivariate statistical model to relate lesion and procedure variables to restenosis. J Am Coll Cardiol 1991;18:647.

\section{Appendix}

Scoring system for left ventricle performance Left ventriculogram is divided into a total of seven segments: five for the right anterior oblique projection (apical, anterobasal, anterolateral, posterobasal, and inferior) and two for the left anterior oblique projection (septal and posterolateral). Then following points are given for the each segment and the left ventricular performance score is calculated as the sum of these scores.

Normal wall motion: 1 point

Hypokinesia: 2 points

Akinesia: 3 points

Dyskinesia: 4 points

Aneurysm: 5 points 